Walter Sonderegger, David Mannes*, Anders Kaestner, Jan Hovind and Eberhard Lehmann

\title{
On-line monitoring of hygroscopicity and dimensional changes of wood during thermal modification by means of neutron imaging methods
}

\begin{abstract}
European beech (Fagus sylvatica L.) and Norway spruce [Picea abies (L.) Karst.] have been thermally modified in a combined air-steam atmosphere between $70^{\circ} \mathrm{C}$ and $150^{\circ} \mathrm{C}$ and pressures up to $4 \mathrm{bar}$, and the changes of dimensions and moisture contents (MC) of the samples were studied in-situ by means of neutron imaging (NI). This noninvasive testing method offers unique opportunities. NI is highly sensitive for hydrogen and thus well suited for monitoring the $\mathrm{MC}$ changes, although some metals (e.g., $\mathrm{Al}$ ), indispensable for sample environments under high temperature and pressure, are practically transparent to neutrons. The results show that the modification induced changes of $\mathrm{MC}$ and dimensions both in radial and tangential direction can well be determined by NI. Dimensional changes from water saturation to oven-dry state, the sorption isotherms, and the differential swelling were observed. Additionally, the sorption behaviour at $20^{\circ} \mathrm{C}$ was investigated after thermal modification and colour measurements were carried out before and after the thermal treatment.
\end{abstract}

Keywords: beech, colour shift, differential swelling, neutron imaging, sorption, spruce, thermal modification

DOI 10.1515/hf-2014-0008

Received January 10, 2014; accepted April 3, 2014; previously published online May 10, 2014

\section{Introduction}

Superheated steam drying at high temperatures is still an ongoing field of research in wood technology. Advantages

*Corresponding author: David Mannes, Neutron Imaging and Activation Group, Spallation Neutron Source Division, Paul Scherrer Institut, CH-5232 Villigen PSI, Switzerland, Phone: +41-56-310-4610, Fax:+41-56-310-3131, e-mail: david.mannes@psi.ch Walter Sonderegger, Anders Kaestner, Jan Hovind and Eberhard Lehmann: Neutron Imaging and Activation Group, Spallation Neutron Source Division, Paul Scherrer Institut, CH-5232 Villigen PSI, Switzerland are the reduction of drying time, case hardening and lower costs (Yamsaengsung and Tabtiang 2012; Park et al. 2014). Heat treatment is also an important tool to improve dimensional stability and microbial resistance of wood. The high temperature treatment causes a reduction of wood hygroscopicity as well as colour and mechanical property changes combined with mass loss due to chemical changes and a degradation of the wood components. These changes are not only dependent on temperature but also vary with moisture content (MC), treatment time and method, catalysts, wood species and sample dimensions (Stamm 1956; Hill 2006; Esteves and Pereira 2009; Sandberg et al. 2013).

For optimising of the drying procedures at high temperatures, the knowledge of the sorption behaviour is crucial at these temperatures and the therefrom-depending dimensional changes. Due to the difficulties of the experimental determination, the sorption isotherms were often extrapolated from measurements below $100^{\circ} \mathrm{C}$ (e.g., Kauman 1956) and only few experimental investigations exist on sorption isotherms above $100^{\circ} \mathrm{C}$ (e.g., Engelhardt 1979; Kubojima et al. 2003). Consequently, more experimental data are necessary to validate the sorption isotherms.

The heat treatment of wood can be classified as the traditional one with process temperatures between $150^{\circ} \mathrm{C}$ and $260^{\circ} \mathrm{C}$ and the so-called 'accelerated ageing' with temperatures in the range of $100^{\circ} \mathrm{C}-150^{\circ} \mathrm{C}$ (Obataya 2009; Sandberg et al. 2013). In the latter case, a good correlation exists between hygroscopicity reduction and weight loss (WL) of thermally treated and subsequently water extracted wood $\left(90-120^{\circ} \mathrm{C}\right)$ independently of the treatment (dry or steamed) and of the kind of wood (sapwood, heartwood) (Obataya et al. 2006).

The present investigation deals with heat treatment in a combined air-steam atmosphere in the range of accelerated ageing and was performed within the framework of the COST action FP0904: Thermo-Hydro-Mechanical Wood Behaviour and Processing. Its main goal is to improve the knowledge on dimensional and hygroscopicity changes occurring during heat treatment. The project focuses on the 
monitoring of the wood change during the treatment process itself with the method of neutron imaging (NI). This method offers a unique opportunity as it is highly sensitive to hydrogen (and thus for MC changes), whereas some metals (e.g., $\mathrm{Al})$, that are needed for the equipment, are practically transparent to neutrons. These facts allow changes to be determined in hygroscopicity and dimension during the thermal treatment even under high temperature and pressure.

\section{Materials and methods}

\section{Materials and test conditions}

The experiments were carried out at the neutron imaging (NI) facility NEUTRA (Lehmann et al. 2001) of the Paul Scherrer Institut (PSI). The instrument was fed by the spallation neutron source SINQ (Blau et al. 2009). Industrially dried wood specimens of European beech (Fagus sylvatica L.) and Norway spruce [Picea abies (L.) Karst.] were examined. Four different moisture cycles were investigated at five temperatures: $70^{\circ} \mathrm{C}, 90^{\circ} \mathrm{C}, 110^{\circ} \mathrm{C}, 130^{\circ} \mathrm{C}$, and $150^{\circ} \mathrm{C}$ (at cycle 4 only three temperatures: $110^{\circ} \mathrm{C}, 130^{\circ} \mathrm{C}$, and $150^{\circ} \mathrm{C}$ ). In each experiment, two specimens of each species with the dimensions $30 \mathrm{~mm}(\mathrm{t}) \times 30 \mathrm{~mm}$ (r) $\times 5 \mathrm{~mm}$ (l) were treated and tested. Before the tests, all specimens were climatised at normal conditions $\left(20^{\circ} \mathrm{C}\right.$ and $\left.65 \% \mathrm{RH}\right)$ until mass constancy was reached except for cycle 4 , where the specimens were previously water saturated. The mean normal densities of spruce and beech were $476 \mathrm{~kg} \mathrm{~m}^{-3}$ and $685 \mathrm{~kg} \mathrm{~m}^{-3}$, respectively. Cycle 1: The specimens were heated in air to the required temperatures and then conditioned for $60 \mathrm{~min}$ for each humidity level at 80\%, 50\%, 70\%, and $40 \% \mathrm{RH}$ and dried to nearly $0 \% \mathrm{RH}$ by holding the temperature constant. Cycle 2 (sorption cycle): The specimens were heated as in cycle 1 . Then an adsorption-desorption cycle followed at the required temperatures by conditioning the samples during $30 \mathrm{~min}$ (60 $\mathrm{min}$ at $70^{\circ} \mathrm{C}$ and $90^{\circ} \mathrm{C}$ ) for each humidity level at $20 \%, 30 \%, 40 \%, 50 \%$, $60 \%, 70 \%, 80 \%, 90 \%, 70 \%, 50 \%$, and 30\% RH and dried. Cycle 3: The specimens were heated during $30 \mathrm{~min}\left(10 \mathrm{~min}\right.$ at $130^{\circ} \mathrm{C}$ and $150^{\circ} \mathrm{C}$ ) with saturated steam to the required temperature and then conditioned as in cycle 1 at the four humidity levels and dried. Cycle 4: Water saturated specimens were heated and conditioned analogue to cycle 3. For the tests above $100^{\circ} \mathrm{C}$, a constant positive pressure of an air/steam mix corresponding to the required $\mathrm{RH}$ was used during the whole treatment time $\left(110^{\circ} \mathrm{C} / 0.5\right.$ bar, $130^{\circ} \mathrm{C} / 2$ bar, $150^{\circ} \mathrm{C} / 4$ bar $)$.

Before and after the treatments, colour measurements were carried out on all specimens (including 10 reference specimens per species). The colorimetric shift was determined in the CIELAB colour space with a Minolta chromameter CR-200. The measurements were carried out on both cross sections of each specimen. The lightness factor $L^{\star}$ and the chromaticity coordinates $a^{\star}$ and $b^{\star}$ were measured and therefore the total colour deviation $\Delta \mathrm{E}^{\star} \mathrm{ab}$ was determined.

Further, the influence of the different test conditions on adsorption and desorption at $20^{\circ} \mathrm{C}$ was measured subsequently to the radiation tests on all specimens. The sorption tests were carried out in a climate chamber KBWF 720 (Binder GmbH, Tuttlingen, Germany). For adsorption, the specimens were first conditioned at $60^{\circ} \mathrm{C}$ and $10 \% \mathrm{RH}$ for $4 \mathrm{~h}$. Afterwards, the equilibrium moisture content (EMC)
$(<0.1 \%$ mass change within $24 \mathrm{~h}$ ) was determined at 30\%, 40\%, $50 \%, 60 \%, 70 \%, 80 \%$, and $90 \%$ RH. For desorption, the EMC was tested in reverse order and the specimens were ovendried at the end.

\section{Experimental setup}

For the in-situ experiments, a dedicated setup to control the sample environment during the measurements had to be designed and constructed (Figure 1). The centerpiece is the pressurised testing chamber. It was built for temperatures up to $180^{\circ} \mathrm{C}$ and pressures up to 10 bars. The whole chamber is made of aluminium, which is almost transparent for neutrons. Due to its low melting point aluminium is prone to deformations. As a consequence, the chamber walls require a thickness of ca. $11 \mathrm{~mm}$. The bottom and the cover plate are screwed. The specimen holder, where four specimens can be tested in parallel, is fixed to the cover plate (Figure 2a). The steam-air mix is injected laterally at the bottom and passes an aluminium mesh to receive preferably a laminar flow near the test specimens. The testing chamber was wrapped with a HSTD strip heater, which was connected with a HT 20 temperature controller (both: Horst GmbH, Lorsch, Germany). Two combined temperature and humidity sensors HMT 337 (Vaisala Company, Helsinki, Finland), suitable for temperatures between $-20^{\circ} \mathrm{C}$ and $180^{\circ} \mathrm{C}$ and RHs in the range $0-100 \% \mathrm{RH}$, were fixed in the testing chamber above and below the position of the test specimens. The temperature and humidity data were recorded by the software 'HyperTerminal'.

A steel-made mixing chamber for pressures up to 10 bars was connected to the actual testing chamber through a closed loop flow system (constructed and installed together with the high temperature and pressure set-up by ZAG Engineering, Oeschgen, Switzerland). It is heatable up to $180^{\circ} \mathrm{C}$ with heating rods, which were connected with a JCS-33A temperature controller (Shinko Technos Company Limited, Osaka, Japan).

For the steam-air circulation, a magnetic ventilator qualified for high temperatures and pressures (cyclone 075, Büchi AG, Uster, Switzerland) was used. To maintain the temperature within the whole system as constant as possible, it was insulated with rock wool (4-8 cm thick). The mixing and testing chamber were equipped with condensate separators to collect the condensates, which were inevitably produced during the experiments. Due to these features, the vapour was dry in the chambers. Additionally, a safety valve was placed on the side of the mixing chamber. To regulate the steam-air mix during the experiments, steam and compressed air were injected into the mixing chamber from external sources (steam generator, air compressor) by means of manually regulating valves.

Since limited space was available in the NI facility NEUTRA the setup had partially to be placed on its roof. Therefore, the external connections such as hoses for steam (steam induction, regulation, pressure overload), compressed air and condensate as well as the connecting cables for the temperature controllers and the HMT 337 sensors had to be conducted through a funnel in the roof shielding the NEUTRA beamline.

\section{The principle of neutron imaging (NI)}

Neutron imaging is a non-destructive testing method based on the principle of transmission measurements. The observed object is exposed to radiation and the incident radiation is attenuated by 


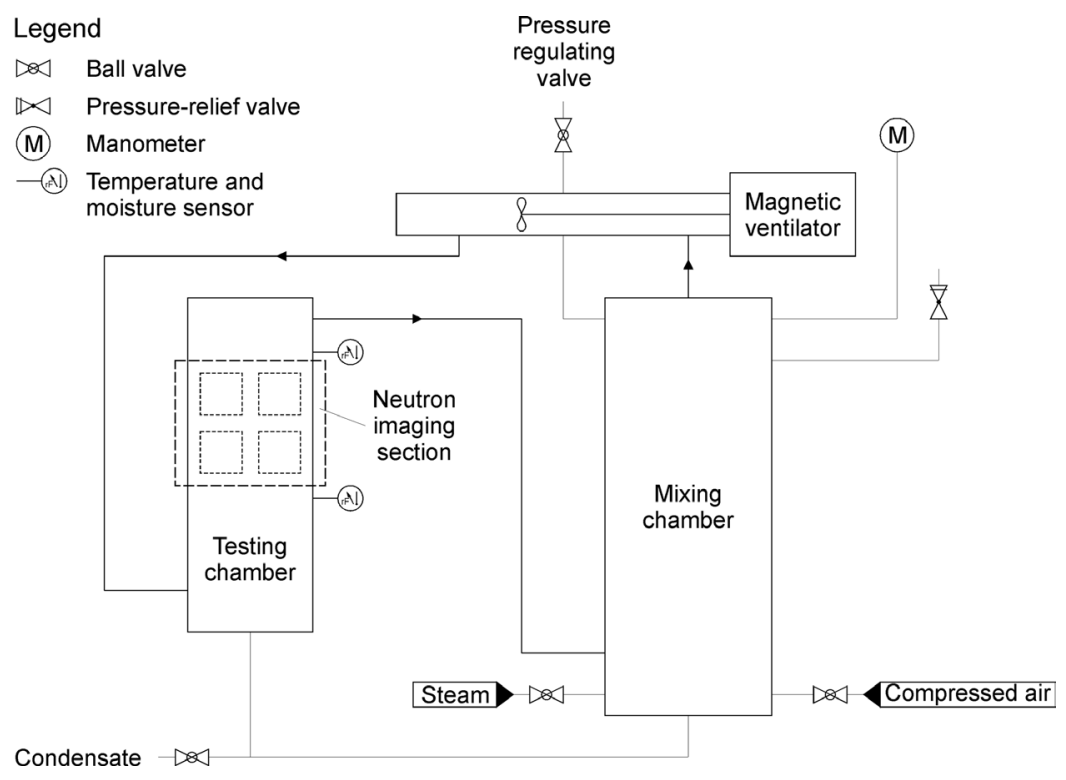

Figure 1 Schematic design of the device for the high temperature and pressure treatment.

the object depending on its composition, structure and density. Subsequently, the transmitted neutron radiation is registered with an imaging detector behind the object (Mannes et al. 2009a).

The attenuation follows Lambert-Beer's-law (Equation 1):

$$
I=I_{0} \cdot e^{-\Sigma \cdot z}
$$

Where $I$ is the intensity of the transmitted radiation, $I_{0}$ the intensity of the incident radiation, $\Sigma$ the attenuation coefficient and $z$ the thickness of the object in beam direction.

Therefore, the neutron transmission $(T)$ and attenuation $(-\ln (T))$ can be calculated as follows (Equations 2+3):

$$
T=\frac{I}{I_{0}}=e^{-\Sigma_{i} \cdot z_{i}}
$$

$$
-\ln (T)=\sum_{i} \cdot z_{i}
$$

The imaging detector for the experiments was a scintillatorCCD-camera system consisting of a $200 \mu \mathrm{m}$ thick ${ }^{6} \mathrm{LiF}: \mathrm{ZnS}$ scintillator, an ANDOR IKON-L CCD-camera with $2048 \times 2048$ pixels $^{2}$ and a $50 \mathrm{~mm}(\mathrm{f} / 1.4 \mathrm{G})$ Nikkor lens. The exposure time was $9 \mathrm{~s}$, the images were cropped to a square with an edge length of $130 \mathrm{~mm}$ and the pixel size in the resulting image was about $100 \mu \mathrm{m} /$ pixel.

\section{Data evaluation}

To evaluate and quantify neutron images, standard correction procedures have to be performed (Mannes et al. 2009b). The images were
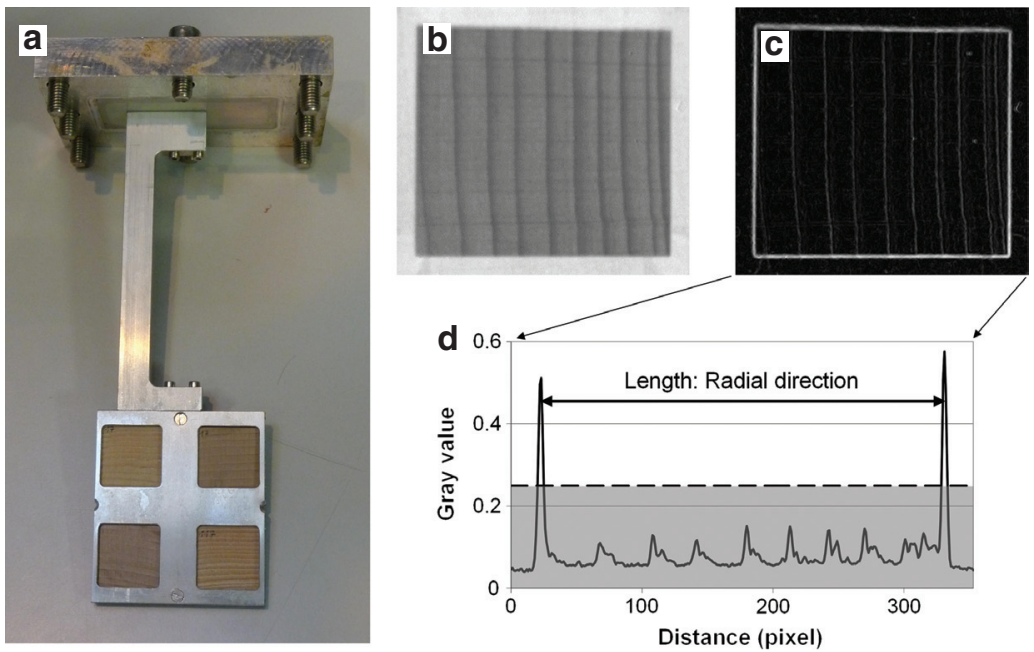

Figure 2 (a) Specimen mount fixed to the cover plate of the testing chamber; (b, c) Original image and edge filtered image (according to Equation 20) of a beech specimen; (d) Tangential projection of the filtered image resulting in the mean length of the radial sample direction [distance between the two peaks above the threshold (dashed line)]. 
corrected by the quantitative neutron imaging correction program (QNI) developed by Hassanein (2006): a) dark current correction caused by the camera background; b) flat field correction; c) median filtering and spot cleaning (filter width: 3 pixels, threshold: 10\%); d) referencing to the start image.

The analysis of the corrected images was carried out with the image data processing program Fiji (Schindelin et al. 2012). For every experimental run each of the four specimens was cropped separately with some surrounding area in the acquired images. In each of the cropped stacks, the sample images were aligned with the plugin 'StackReg' with the transformation specification 'Rigid Body' (Thévenaz et al. 1998). Then, a region of interest (ROI) was selected covering the whole area of the specimen in the most swollen state.

Thereby, the mean attenuation of the ROI could be defined as the sum of the attenuations of the particular radiated materials (Equations 4+5). For the specimen in the maximal swollen state:

$$
\begin{aligned}
-\ln \left(T_{\text {wet }}\right)= & \sum_{I} \cdot z_{I}+\sum_{A l} \cdot z_{A I}+\sum_{H . w e t} \cdot z_{H . w e t} \\
& +\sum_{w} \cdot z_{H . w e t}
\end{aligned}
$$

For the specimen in the dry state [low (or zero) MC]:

$$
-\ln \left(T_{d r y}\right)=\Sigma_{I} \cdot z_{I}+\Sigma_{A l} \cdot z_{A l}+\frac{A^{\prime}}{A} \Sigma_{H . d r y} \cdot z_{H . d r y}+\frac{A^{\prime}}{A} \Sigma_{w} \cdot z_{w . d r y}
$$

where $T_{\text {wet }}$ and $T_{d r y}$ are the transmissions of the wet and the dry specimens, $A$ the whole area of the ROI, $A^{\prime}$ the area of the dry wood specimen, $\Sigma$ the attenuation coefficient and $z$ the thickness of a material with the indices: $I=$ isolation material (here rockwoll), $A l=$ aluminium, H.wet and H.dry=wood in the maximal swollen and in the dry state, respectively, $w=$ water and $w . w e t$ and $w \cdot d r y=$ water in the wet and dry wood specimen, respectively.

The density of the wood material (without water fraction) differs between the two states due to shrinkage effects and can be described as follows (Equations 6+7):

$$
\begin{gathered}
\rho_{H . w e t}=\frac{m_{H}}{A \cdot z_{H . w e t}} \\
\rho_{H . d y}=\frac{m_{H}}{A^{\prime} \cdot z_{H . d r y}}
\end{gathered}
$$

where $\rho_{\text {H.wet }}$ and $\rho_{H . d r y}$ are the densities of the wood material (ovendry) at the maximal swollen and at the dry state and $m_{H}$ is the oven dry mass of the wood specimen.

Due to the fact that the attenuation coefficient of wood corresponds directly with its density (Mannes et al. 2009a), the attenuation coefficients of the two states differ. The attenuation coefficient of the dry state can be derived from the attenuation coefficient of the maximal swollen state as follows (Equation 8):

$$
\Sigma_{H . d r y}=\Sigma_{H . w e t} \cdot \frac{\rho_{H . d r y}}{\rho_{H . w e t}}=\Sigma_{H . w e t} \cdot \frac{A \cdot z_{H . w e t}}{A^{\prime} \cdot z_{H . d r y}}
$$

Through insertion in Equation 5 and reduction, it results (Equation 9):

$$
-\ln \left(T_{d r y}\right)=\Sigma_{I} \cdot z_{I}+\Sigma_{A l} \cdot z_{A l}+\Sigma_{H . w e t} \cdot z_{H . w e t}+\frac{A^{\prime}}{A} \Sigma_{w} \cdot z_{w . d r y}
$$

Therefore it follows that the attenuation based on the wood material of the wood specimen is equal to that of Equation 4 and is therefore independent of the state (wet or dry). Thus, through subtraction of Equation 9 from Equation 4, it remains only the attenuation of the water fraction (Equation 10):

$$
-\ln \left(\frac{T_{w e t}}{T_{d r y}}\right)=\Sigma_{w} \cdot z_{w . w e t}+\frac{A^{\prime}}{A} \Sigma_{w} \cdot z_{w . d r y}=\Sigma_{w} \cdot\left(z_{w . w e t}-\frac{A^{\prime}}{A} \cdot z_{w . d r y}\right)
$$

The water concentration $(c)$ in the wood is based on the volumetric content and can be defined as the ratio of the water to the wood thickness at a given state (Equation 11):

$$
\begin{gathered}
c=\frac{z_{w}}{z_{H}} \\
M C=\frac{m_{w e t}-m_{0}}{m_{0}} \\
M C=\frac{\rho_{w}}{\rho_{H}} \cdot c
\end{gathered}
$$

Due to swelling and shrinkage of wood in connection with water uptake and release, commonly the $M C$ is used as unit in the field of wood science instead of the water concentration. The $M C$ is based on the wood mass at oven-dry conditions, which remains constant in contrast to the volume and is defined as follows (DIN 52183) (Equation 12), where $m_{\text {wet }}$ is the mass of the wood at wet conditions (this means the wood mass including the water fraction) and $m_{0}$ the oven-dried mass of the wood. The water concentration can be converted into $M C$ at a given state as follows (Equation 13), where $\rho_{w}$ and $\rho_{H}$ are the densities of water and of wood, respectively. Thus, the $M C$ of the two states can be calculated as follows (Equations 14+15) considering Equations 6 and 7:

$$
\begin{aligned}
& M C_{\text {wet }}=\frac{\rho_{w}}{\rho_{H \cdot w e t}} \cdot \frac{z_{w \cdot w e t}}{z_{H \cdot w e t}}=\frac{\rho_{w} \cdot z_{w \cdot w e t} \cdot A}{m_{H}} \\
& M C_{d r y}=\frac{\rho_{w}}{\rho_{H . d r y}} \cdot \frac{z_{w \cdot d r y}}{z_{H . d r y}}=\frac{\rho_{w} \cdot z_{w \cdot d r y} \cdot A^{\prime}}{m_{H}}
\end{aligned}
$$

Therefore, $z_{\text {w.wet }}$ and $z_{\text {w.dry }}$ can be defined as follows (Equations 16+17):

$$
\begin{aligned}
& z_{w \cdot w e t}=\frac{M C_{w e t} \cdot m_{H}}{\rho_{w} \cdot A} \\
& z_{w . d r y}=\frac{M C_{d r y} \cdot m_{H}}{\rho_{w} \cdot A^{\prime}}
\end{aligned}
$$

Insertion of Equations 16 and 17 in Equation 10 results in (Equation 18):

$$
\begin{aligned}
-\ln \left(\frac{T_{w e t}}{T_{d r y}}\right) & =\Sigma_{w} \cdot\left(z_{w \cdot w e t}-\frac{A^{\prime}}{A} z_{w \cdot d r y}\right)=\Sigma_{w} \cdot\left(\frac{M C_{w e t} \cdot m_{H}}{\rho_{w} \cdot A} \cdot \frac{A^{\prime}}{A} \cdot \frac{M C_{d r y} \cdot m_{H}}{\rho_{w} \cdot A^{\prime}}\right) \\
& =\Sigma_{w} \cdot\left(M C_{w e t}-M C_{d r y}\right) \cdot \frac{m_{H}}{\rho_{w} \cdot A}
\end{aligned}
$$

Through conversion, the MC differences between two images can be calculated as follows (Equation 19):

$$
M C_{w e t}-M C_{d r y}=-\ln \left(\frac{T_{w e t}}{T_{d r y}}\right) \cdot \frac{\rho_{w} \cdot A}{\Sigma_{w} \cdot m_{H}}
$$


For the tests, an experimentally determined attenuation coefficient $\Sigma_{w}=2.2 \mathrm{~cm}^{-1}$ was used.

\section{Dimensional changes}

To determine the dimensional changes, the edges of the specimen in each image were detected (Figure 2b, c) by means of a gradient filter, where the intensity changes within an image were highlighted with following weighting factors (Equation 20):

$$
G_{x}=\left(\begin{array}{ccc}
-3 & 0 & 3 \\
-10 & 0 & 10 \\
-3 & 0 & 3
\end{array}\right) \cdot A \text { and } G_{y}=\left(\begin{array}{ccc}
-3 & -10 & -3 \\
0 & 0 & 0 \\
3 & 10 & 3
\end{array}\right) \cdot A
$$

Then, the filtered images were projected in the $r$ and the $t$ directions, which each resulted in a line with two significant peaks, which mark the mean dimensional border of the sample (Figure $2 \mathrm{~d}$ ). To determine the subpixel specific positions of these two maxima, the centre of gravity was calculated in two regions of interest, which each contained a single edge.

\section{Results and discussion}

\section{In-situ measurements during heat treatment}

With the experimental setup, the changes of MC and the dimensional changes in radial $(\mathrm{r})$ and tangential $(\mathrm{t})$ directions could be determined. Figure 3 shows these changes on one beech and spruce specimen, respectively, from water saturation to oven dry at a temperature of $150^{\circ} \mathrm{C}$. During the heating phase from room temperature to $150^{\circ} \mathrm{C}$, a clear increase in t direction was measured on both species whereas in $\mathrm{r}$ direction the dimension remained nearly stable which may have been influenced by thermal wood expansion (Sonderegger and Niemz 2006; Miki et al. 2014) and treatment pressure. These characteristics were observed on all specimens of cycle 4. The tendency was higher for beech than for spruce wood and more pronounced at elevated temperatures. Further, the t swelling during the heating phase increased with increasing temperature whereas the $r$ swelling decreased (Table 1). During drying, the $t$ shrinkage was nearly three times as high as the $\mathrm{r}$ shrinkage for beech, which induced several cracks in $r$ direction along the wood rays. Without these cracks, the shrinkage from water saturation to ovendry should be even higher (up to $25 \%$ ) which is about twice as high than average shrinkage at room temperature (Wagenführ 2007) and can be explained with the strong heat treatment. For spruce, in contrast, the t shrinkage is only twice as high as the $r$ shrinkage and clearly lower than for beech (Table 1).
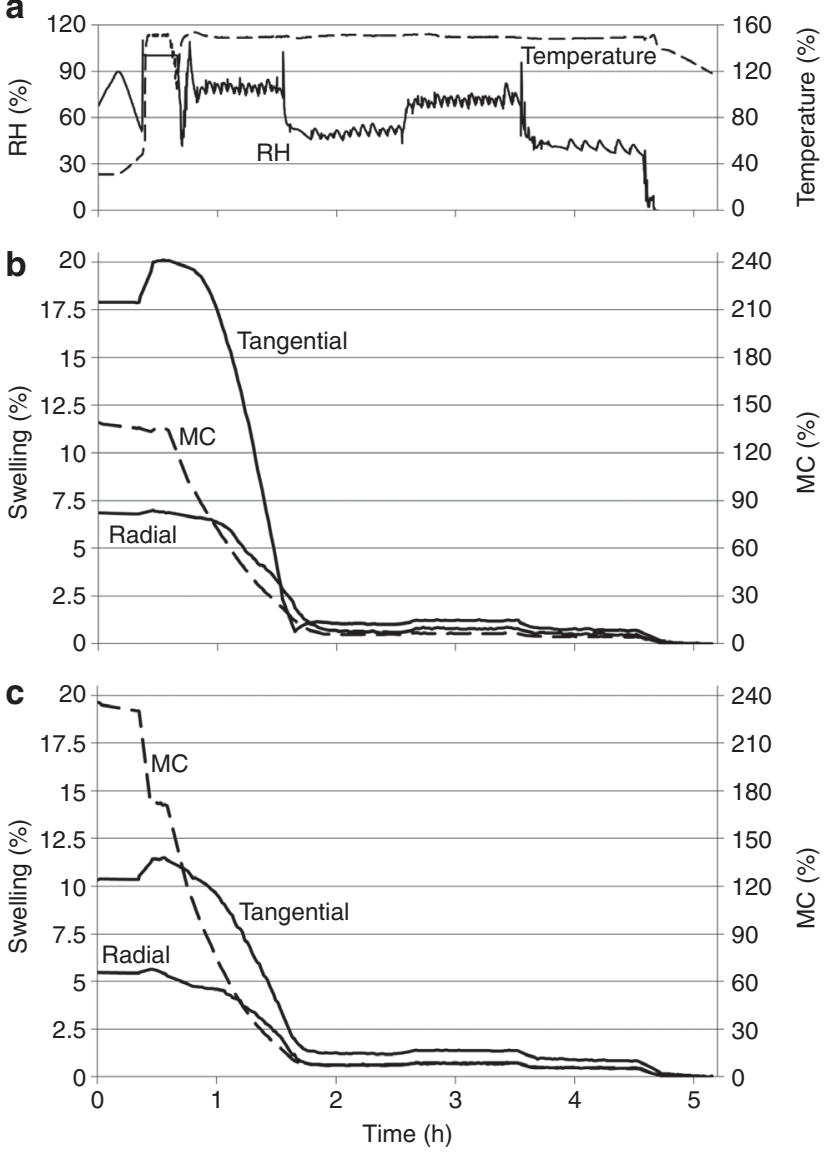

Figure 3 Dimensional and moisture content (MC) changes of beech (b) and spruce (c) wood during cycle 4 at $150^{\circ} \mathrm{C}$; (a) shows the corresponding $\mathrm{RH}$ and temperature curves.

Table 2 shows the differential swelling during the treatment depending on cycle and temperature determined from the slope according to the regression curve $\mathrm{y}=\mathrm{a} \cdot \mathrm{x}+\mathrm{b}$, where $\mathrm{x}$ is the MC [\%], $\mathrm{y}$ the swelling [\%], a the slope and $\mathrm{b}$ the y-intercept. For the regression curves, the equilibrium moisture contents (EMC) at each hygroscopic level and the corresponding swelling were determined by means of the NI evaluation based on the mean

Table 1 Swelling during the heating phase $\left(\mathrm{Sw}_{\mathrm{h}}\right)$ depending on the final temperature $(\mathrm{T})$ and maximal swelling $\left(\mathrm{Sw}_{\max }\right)$ at water saturation relating to the ovendry state.

\begin{tabular}{|c|c|c|c|c|c|c|c|c|}
\hline & \multicolumn{4}{|c|}{ Spruce } & \multicolumn{4}{|r|}{ Beech } \\
\hline & & Rad. & & Tang. & & Rad. & & Tang. \\
\hline $\begin{array}{r}\mathrm{T} \\
\left({ }^{\circ} \mathrm{C}\right)\end{array}$ & $\begin{array}{l}S w_{h} \\
(\%)\end{array}$ & $\begin{array}{r}S w_{\max } \\
(\%)\end{array}$ & $\begin{array}{l}S w_{h} \\
(\%)\end{array}$ & $\begin{array}{r}\mathrm{Sw}_{\max } \\
(\%)\end{array}$ & $\begin{array}{l}S w_{h} \\
(\%)\end{array}$ & $\begin{array}{r}S w_{\max } \\
(\%)\end{array}$ & $\begin{array}{l}S w_{h} \\
(\%)\end{array}$ & $\begin{array}{r}S_{\text {max }} \\
(\%)\end{array}$ \\
\hline 110 & 0.40 & 5.6 & 0.75 & 10.7 & 0.23 & 5.58 & 1.02 & 17.5 \\
\hline 130 & 0.35 & 5.83 & 0.85 & 11.0 & -0.13 & 5.9 & 1.58 & 19.7 \\
\hline 150 & 0.01 & 5.96 & 1.22 & 12.1 & 0.08 & 7.16 & 1.95 & 18.8 \\
\hline
\end{tabular}


Table 2 Differential swelling depending on temperature (T) between $0 \%$ and $70 \%$ RH (cycle 4), $0 \%$ and $80 \%$ RH (cycles 1 and 3 ) and $0 \%$ and $90 \%$ RH (cycle 2).

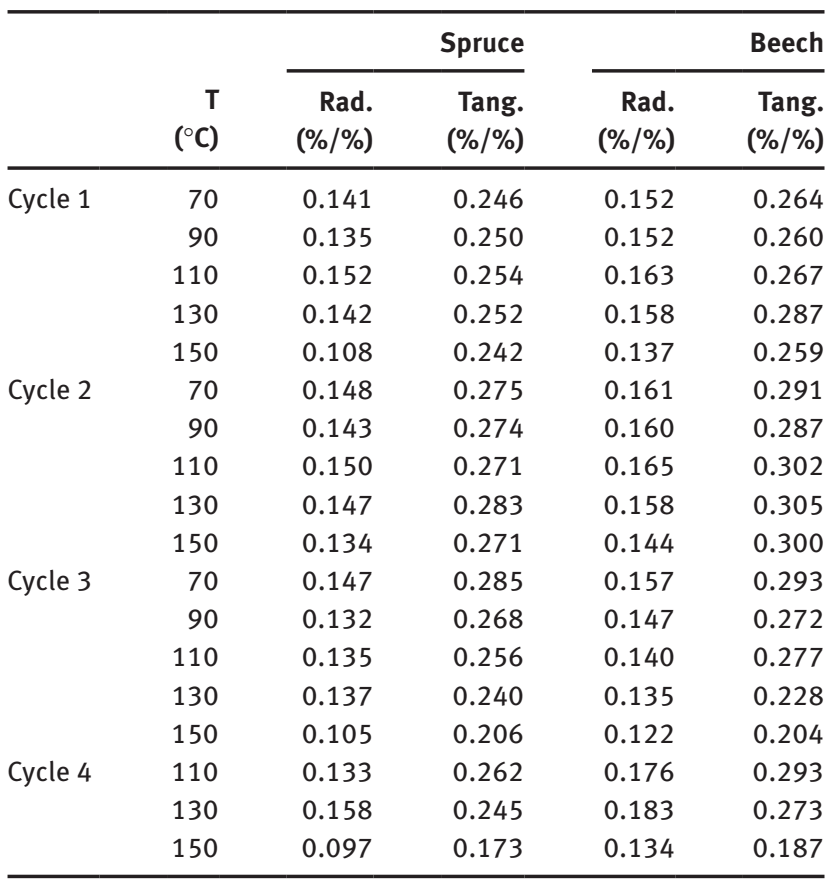

values of the two specimens per species and test. For the dry heated specimens (cycles 1 and 2) only little variation was found between $70^{\circ} \mathrm{C}$ and $130^{\circ} \mathrm{C}$, but at $150^{\circ} \mathrm{C}$ the differential swelling in $\mathrm{r}$ direction was diminished, more for spruce than for beech. The values of cycle 2 are about $5-10 \%$ higher compared to these of cycle 1 , although the treatment time was longer. In contrast the specimens heated with steam (cycles 3 and 4) showed a decrease of the differential swelling with increasing temperature in the whole measured temperature range, which was more distinct in $\mathrm{t}$ than in $\mathrm{r}$ direction. The calculated differential swelling averaged over all cycles and temperatures was about a quarter smaller compared with literature values measured at room temperature but it has to be remembered that high variations can exist within one wood species and the swelling is highly influenced by density (Niemz 1993).

The coefficients of determination $\left(\mathrm{R}^{2}\right)$ lie between 0.97 and 0.99 with the exception of beech wood at cycle $2\left(\mathrm{R}^{2}\right.$ : 0.93-0.99). There, a hysteresis effect of swelling depending on $\mathrm{MC}$ was found in $\mathrm{t}$ direction for all temperatures in contrast to investigations at $20^{\circ} \mathrm{C}$ where a hysteresis effect was found in $\mathrm{r}$ direction (Sonderegger et al. 2008). Figure 4 shows this effect at a temperature of $110^{\circ} \mathrm{C}$.

Figure 5 shows the sorption isotherms between $70^{\circ} \mathrm{C}$ and $150^{\circ} \mathrm{C}$ of beech and spruce wood determined from cycle 2. Due to mass loss (ML) during the treatment, the

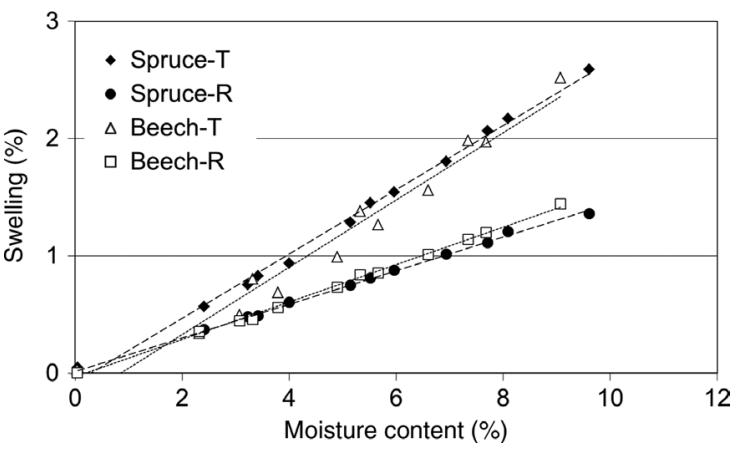

Figure 4 Swelling in relation to moisture content (MC) at $90^{\circ} \mathrm{C}$ according to cycle 2 (mean values of two specimens) and the corresponding slopes (=differential swelling). T, tangential; R, radial.

sorption curves between $110^{\circ} \mathrm{C}$ and $150^{\circ} \mathrm{C}$ were corrected by a linear ML factor, that was experimentally evaluated from the measurements by comparing the oven-dry state after the heating phase with that at the end of the measurement. At $150^{\circ} \mathrm{C}$, a ML factor of $0.234 \% \mathrm{~h}^{-1}$ and $0.209 \% \mathrm{~h}^{-1}$ was applied for spruce and for beech, respectively. Due to measurement inaccuracy at $110^{\circ} \mathrm{C}$ and $130^{\circ} \mathrm{C}$, this factor was multiplied with 0.2 at $110^{\circ} \mathrm{C}$ and 0.6 at $130^{\circ} \mathrm{C}$. The standard deviation of the MC per RH step increased with increasing temperature due to manual $\mathrm{RH}$ regulation and increasing adaption celerity of the MC oscillation and amounts up to $0.4-0.5 \%$ water concentration (or about

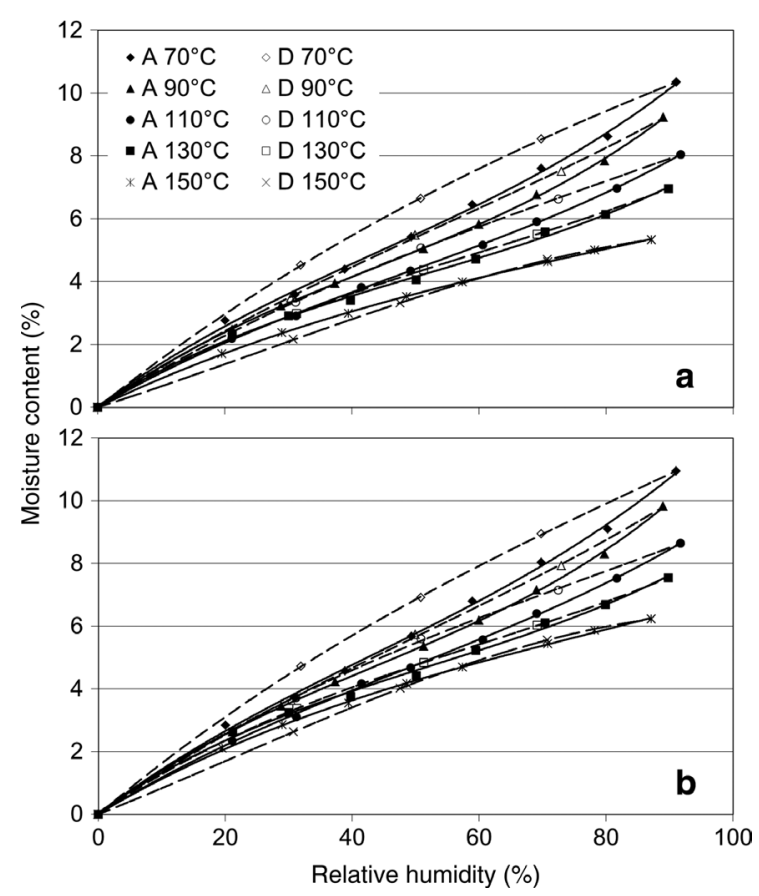

Figure 5 Sorption isotherms of beech (a) and spruce (b) wood between $70^{\circ} \mathrm{C}$ and $150^{\circ} \mathrm{C}$ determined through neutron radiation. A, adsorption; D, desorption. 
$1 \% \mathrm{MC}$ for spruce and $0.75 \% \mathrm{MC}$ for beech). The sorption isotherms of both wood species decreased with increasing temperature, which was expected and agrees with measurements of Engelhardt (1979) and Kubojima et al. (2003). However, the reduction observed by Kubojima et al. (2003) was clearly higher compared to the own measurements and those of Engelhardt (1979), maybe due to longer exposure to the treatment. Also, a slight hysteresis was measured up to $110^{\circ} \mathrm{C}$.

\section{Sorption measurements after the treatment}

Figure 6 shows the adsorption and desorption behaviour at $20^{\circ} \mathrm{C}$ of both wood species after the treatments as a function of temperature. For spruce, the sorption isotherms above a treatment of $90^{\circ} \mathrm{C}$ clearly decrease with increasing temperature for both, adsorption and desorption. In contrast, the specimens treated at $70^{\circ} \mathrm{C}$ and $90^{\circ} \mathrm{C}$ show only in the range between $30 \%$ and $90 \% \mathrm{RH}$ lower adsorption isotherms than the untreated specimens. For desorption, the three isotherms (untreated, $70^{\circ} \mathrm{C}$, and $90^{\circ} \mathrm{C}$ ) nearly coincide. For beech, the sorption isotherms decreased with increasing temperature over the whole measuring range. However, like spruce, the decrease with increasing temperature was lower at desorption than at adsorption. This different behaviour for adsorption and desorption can already be found in the works of Egner in Kollmann and Schneider (1963) and Tiemann in Sandberg et al. (2013). It can be interpreted that heat induced hygroscopicity changes are partly reversible by moistening at high RH (Obataya 2009; Hill et al. 2012).

\section{Colour measurements}

Figure 7 shows the colour changes before and after the treatment according to the CIELAB colour space system depending on temperature and kind of treatment. Thereby, the values at $20^{\circ} \mathrm{C}$ represent the colour shift of the reference specimens which is negligible for the lightness factor $\left(L^{\star}\right)$ as well as for the two chromaticity coordinates $\left(a^{\star}, b^{\star}\right)$. Concerning the heat treatment, the dry heated specimens (cycles 1 and 2) show clearly lower colour shift (relative to all components: $\mathrm{L}^{\star}, \mathrm{a}^{\star}, \mathrm{b}^{\star}$ ) than the specimens heated with steam (cycles 3 and 4) that corresponds to a higher wood degradation of the latter (Stamm 1956). For the dry heated specimens, the reduction of $\mathrm{L}^{\star}$ was small only up to $110^{\circ} \mathrm{C}$ but increased exponentially at higher temperatures which agreed with measurements carried out by Bekhta and Niemz (2003). The slightly higher reduction of cycle 2 compared with cycle 1 is induced by the longer exposure time. The specimens heated with steam (cycle 3) show a higher reduction between $110^{\circ} \mathrm{C}$ and $150^{\circ} \mathrm{C}$ compared with the dry heated specimens which was about twice as high for spruce and to about five times higher for beech. This reduction corresponds well with values of steamed beech wood by Riehl et al. (2002). The highest reduction is visible on the water saturated specimens (cycle 4), for spruce at all temperatures and for beech at $110^{\circ} \mathrm{C}$. The colour shift within the chromaticity coordinates was very low in contrast to the reduction of $\mathrm{L}^{\star}$. Therefore, the total colour deviation $\Delta \mathrm{E}^{\star}$ ab was similar to the reduction of $\mathrm{L}^{\star}$ with positive sign. Whereas a small shift to red $\left(+a^{\star}\right)$ was measured (with exception of the dry heated beech specimens), the shift to yellow $\left(+b^{\star}\right)$ with

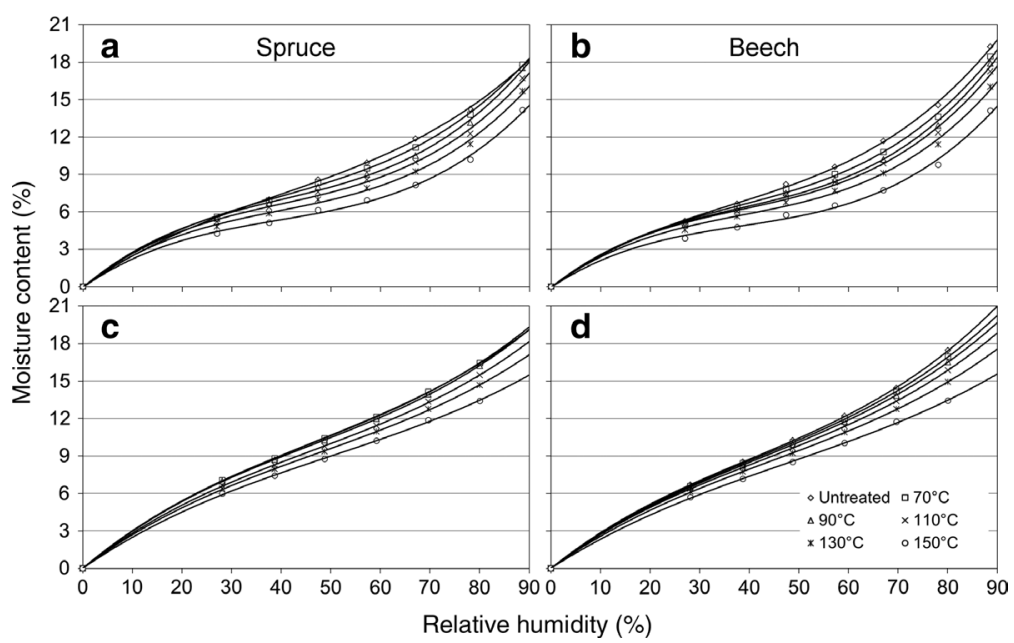

Figure 6 Adsorption $(a, b)$ and desorption $(c, d)$ isotherms at $20^{\circ} \mathrm{C}$ of untreated and at different temperatures treated spruce (a, c) and beech (b, d) wood. 


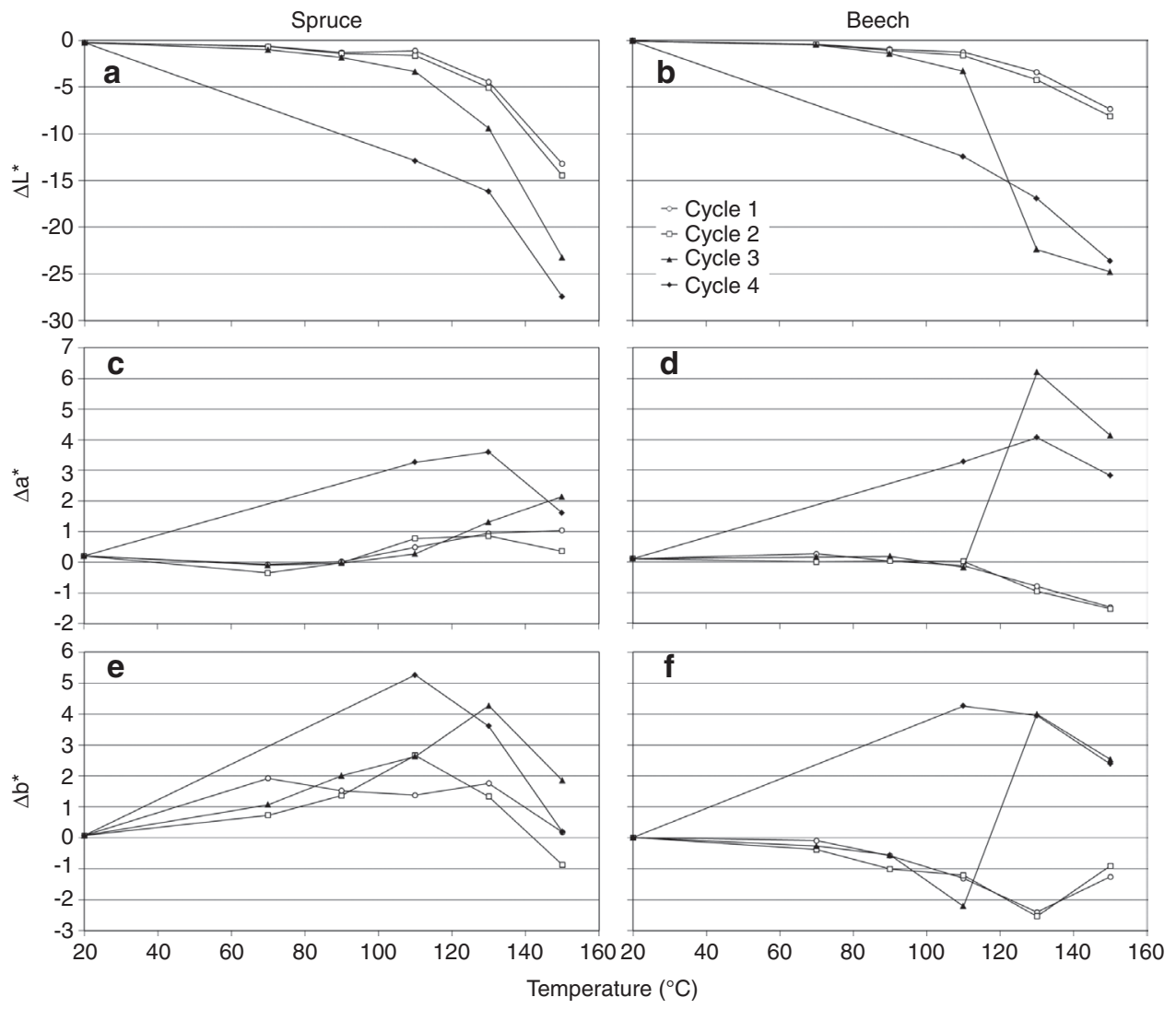

Figure 7 Colour changes of the lightness factor $\left(L^{\star}\right)$ and the chromaticity coordinates $\left(a^{\star}, b^{\star}\right)$ of spruce $(a, c, e)$ and beech wood $(b, d, f)$ depending on the treatment and the temperature.

increasing temperature turned from black to blue $\left(-b^{\star}\right)$ at $150^{\circ} \mathrm{C}$ for all spruce specimens and the beech specimens of cycle 4 (and partially cycle 3 ). In contrast, the beech specimens of cycles 1 and 2 showed reverse $b^{\star}$-shift. The alternating shift of the chromaticity coordinates as a function of treatment time and temperature was also shown by González-Peña and Hale (2009) and Matsuo et al. (2011) and depended on the decrease in lightness.

\section{Conclusions}

The changes in MC and dimensions, which occured during the actual heat treatment, could be measured and quantified by neutron imaging (NI) in-situ. Expectedly, the MC and RH influenced the hygroscopicity and colour change etc. From water saturation to oven-dried state, the tangential shrinkage was up to $20 \%$ for beech. The darkening of the water-saturated samples (both beech and spruce) was two to five times higher compared with that of the dry samples. NI provided the unique possibility of in-situ MC and space measurements during heat treatment. This opens the door for further investigations within the field of thermal wood modification. One new aspect may be the observation of dimensional and MC changes close to the fibre saturation point, which highly influence the treatment results.

Acknowledgments: The authors thank the Swiss State Secretariat for Education and Research for the financial support of the project. Further acknowledgement goes to the Wood Physics Group of the Institute for Building Materials at ETH Zurich, Switzerland for helping with the sample preparation and the colour measurements.

\section{References}

Bekhta, P., Niemz, P. (2003) Effect of high temperature on the change in color, dimensional stability and mechanical properties of spruce wood. Holzforschung 57:539-546.

Blau, B., Clausen, K.N., Gvasaliya, S., Janoschek, M., Janssen, S., Keller, L., Roessli, B., Schefer, J., Tregenna-Piggott, Ph., Wagner, W., Zaharko, O. (2009) The Swiss spallation neutron source SINQ at Paul Scherrer Institut. Neutron News 20:5-8. 
DIN 52183 Prüfung von Holz; Bestimmung des Feuchtigkeitsgehaltes. Beuth Verlag GmbH, Berlin, 1977.

Engelhardt, F. (1979) Untersuchungen über die Wasserdampfsorption durch Buchenholz im Temperaturbereich von 110 bis $170^{\circ}$ C. Holz Roh Werkst. 37:99-112.

Esteves, B.M., Pereira, H.M. (2009) Wood modification by heat treatment: a review. BioResources 4:370-404.

González-Peña, M.M., Hale, M.D.C. (2009) Colour in thermally modified wood of beech, Norway spruce and Scots pine. Part 1: Colour evolution and colour changes. Holzforschung 63:385-393.

Hassanein, R.K. Correction methods for the quantitative evaluation of thermal neutron tomography. Dissertation, ETH Zurich, Zurich, 2006.

Hill, C.A.S. Wood modification: Chemical, thermal and other processes. John Wiley \& Sons, Chichester, 2006.

Hill, C.A.S., Ramsay, J., Keating, B., Laine, K., Rautkari, L., Hughes, M., Constant, B. (2012) The water vapour sorption properties of thermally modified and densified wood. J. Mater. Sci. 47:3191-3197.

Kauman, W.G. (1956) Equilibrium moisture content relations and drying control in superheated steam drying. Forest Prod. J. 6:328-332.

Kollmann, F., Schneider, A. (1963) Über das Sorptionsverhalten wärmebehandelter Hölzer. Holz Roh Werkst. 21:77-85.

Kubojima, Y., Suzuki, Y., Tonosaki, M., Ishikawa, A. (2003) Moisture content of green wood in high temperature water vapor. Holzforschung 57:634-638.

Lehmann, E.H., Vontobel, P., Wiezel, L. (2001) Properties of the radiography facility NEUTRA at SINQ and its potential for use as European reference facility. Nondestruct. Test. Eva. 16:191-202.

Mannes, D., Josic, L., Lehmann, E., Niemz, P. (2009a) Neutron attenuation coefficients for non-invasive quantification of wood properties. Holzforschung 63:472-478.

Mannes, D., Sonderegger, W., Hering, S., Lehmann, E., Niemz, P. (2009b) Non-destructive determination and quantification of diffusion processes in wood by means of neutron imaging. Holzforschung 63:589-596.

Matsuo, M., Yokoyama, M., Umemura, K., Sugiyama, J., Kawai, S., Gril, J., Kubodera, S., Mitsutani, T., Ozaki, H., Sakamoto, M., Imamura, M. (2011) Aging of wood: Analysis of color changes during natural aging and heat treatment. Holzforschung 65:361-368.

Miki, T., Sugimoto, H., Furuta, Y., Shigematsu, I., Kanayama, K. (2014) Anomalous thermal expansion behaviors of wood under dry and low-temperature conditions. Holzforschung 68:567-574.
Niemz, P. Physik des Holzes und der Holzwerkstoffe. DRW-Verlag, Leinfelden-Echterdingen, 1993.

Obataya, E. (2009) Effects of ageing and heating on the mechanical properties of wood. In: Wood Science for Conservation of Cultural Heritage. Ed. Uzielli, L. Proceedings of the International Conference held by COST Action IE0601, 8-10 November, Florence, Italy, pp. 16-23.

Obataya, E., Shibutani, S., Hanata, K., Doi, S. (2006) Effects of high temperature kiln drying on the practical performances of Japanese cedar wood (Cryptomeria japonica) I: changes in hygroscopicity due to heating. J. Wood Sci. 52:33-38.

Park, Y., Eom, C.-D., Han, Y., Park, J.-H., Chang, Y.-S., Yang, S.-Y., Choi, J.-W., Yeo, H. (2014) Combined treatment of green pitch pine wood by heat and superheated steam and the effects on physical properties of the products. Holzforschung 68:327-335.

Riehl, T., Welling, J., Frühwald, A. Druckdämpfen von Schnittholz. Arbeitsbericht des Instituts für Holzphysik und mechanische Technologie des Holzes Nr. 2002/01, Bundesforschungsanstalt für Forst- und Holzwirtschaft, Hamburg, 2002.

Sandberg, D., Haller, P., Navi, P. (2013) Thermo-hydro and thermohydro-mechanical wood processing: An opportunity for future environmentally friendly wood products. Wood Mat. Sci. Eng. 8:64-88.

Schindelin, J., Arganda-Carreras, I., Frise, E., Kaynig, V., Longair, M., Pietzsch, T., Preibisch, S., Rueden, C., Saalfeld, S., Schmid, B., Tinevez, J.-Y., White, D.J., Hartenstein, V., Eliceiri, K., Tomancak, P., Cardona, A. (2012) Fiji: an open-source platform for biological-image analysis. Nat. Methods 9:676-682.

Sonderegger, W., Niemz, P. (2006) Untersuchungen zur Quellung und Wärmedehnung von Faser-, Span- und Sperrholzplatten. Holz Roh Werkst. 64:11-20.

Sonderegger, W., Alter, P., Niemz, P. (2008) Untersuchungen zu ausgewählten Eigenschaften von Fichtenklangholz aus Graubünden. Holz Roh Werkst. 66:345-354.

Stamm, A.J. (1956) Thermal degradation of wood and cellulose. Ind. Eng. Chem. 48:413-417.

Thévenaz, P., Ruttimann, U.E., Unser, M. (1998) A pyramid approach to subpixel registration based on intensity. IEEE T. Image Process. 7:27-41.

Wagenführ, R. Holzatlas. $6^{\text {th }}$ edition. Carl Hanser Verlag, München, 2007.

Yamsaengsung, R., Tabtiang, S. (2012) Hybrid drying of rubberwood using superheated steam and hot air in a pilot-scale. Drying Technol. 29:1170-1178. 